DOCTRINA

\title{
Nuevas formas de comunicación en la relación directa y regular: Salidas al extranjero
}

\author{
New forms of communication in the direct \\ and regular relationship: Outings abroad
}

\author{
Constanza Astudillo Meza (iD \\ Universidad Santo Tomás, Chile
}

Alexis Mondaca Miranda
Universidad de Talca, Chile

RESUMEN Este artículo tiene por objeto analizar tanto la utilización como la relevancia de las modernas formas de comunicación en el contexto del ejercicio de la relación directa y regular, particularmente a propósito de las autorizaciones para salidas prolongadas o definitivas al extranjero de las madres titulares del cuidado personal acompañadas de sus hijos o hijas. En este sentido, se propone no circunscribir el contenido de la nombrada relación a las visitas de carácter presencial. Se estudian, además, los efectos que en la materia ha provocado la excepcional situación constituida por la pandemia por covid-19. Para lo anterior, se ha tomado en cuenta las disposiciones legales pertinentes, la doctrina especializada y la jurisprudencia de los tribunales superiores de justicia de Chile.

PALABRAS CLAVE Nuevas formas de comunicación, interés superior del niño, relación directa y regular, covid-19.

ABSTRACT The purpose of this article is to analyze both the use and the relevance of modern forms of communication in the context of the exercise of the direct and regular relationship, particularly with regard to the authorizations for prolonged or definitive departures abroad of mothers with personal care accompanied by their children. In this sense, it is proposed not to circumscribe the content of the aforementioned relationship to face-to-face visits. The effects of the exceptional situation caused by the Covid-19 pandemic are also studied. For the above, the relevant legal provisions, the specialized doctrine and the jurisprudence of the chilean high courts of justice have been taken into account.

KEYWORDS New forms of communication, best interests of the child, contact, Covid-19. 


\section{Introducción}

Este artículo trata el derecho-deber de mantener una relación directa y regular, esto es, el régimen comunicacional existente entre padres e hijos e hijas, ello en un contexto determinado: las migraciones al extranjero realizadas por madres acompañadas de sus hijos e hijas, sean estos o estas niños, niñas o adolescentes (NNA), escenario en el que han adquirido especial relevancia las tecnologías de la información. La relación directa y regular no puede comprenderse plenamente sin considerar en el análisis el régimen de cuidado personal. Ambos institutos miran al interés del NNA, se trata de dos formas de relacionarse con estos, uno de modo habitual y constante, el otro, según la periodicidad que se determine en el régimen específico (Acuña, 2020: 87). Por lo anterior, dedicaremos algunas líneas a la disciplina del cuidado personal en nuestro derecho de familia.

En el derecho de familia de Chile, según lo prescrito en el inciso primero del artículo 224 del Código Civil, el derecho-deber de cuidado personal de los hijos, «toca de consuno a los padres, o al padre o madre sobreviviente». La ley no define qué se entiende por cuidado personal, pero, según indica la mayoría de la doctrina especializada, este hace referencia a la convivencia física usual con el NNA y exige el aseguramiento de su crianza y educación (Lennon y Lovera, 2011: 137). ${ }^{1}$

Si los padres viven separados, para determinar el cuidado personal debe distinguirse entre la atribución convencional, legal y judicial. En conformidad a lo regulado en el inciso primero del artículo 225 del Código Civil, los padres de común acuerdo podrán establecer que el cuidado personal corresponde a ambos de manera compartida, o al padre o a la madre. ${ }^{2}$ Este acuerdo, añade el precepto citado, establecerá la frecuencia y libertad con que el padre o madre que no tiene el cuidado personal mantendrá una relación directa y regular con los hijos e hijas. Como podemos advertir, el legislador privilegia el acuerdo entre los padres, dado que una solución consensuada (inexistencia de litigios) es beneficiosa para la familia y, especialmente, para el NNA.

Con respecto a la atribución legal, siempre en el supuesto de separación de los padres, a falta de acuerdo entre estos prescribe el inciso tercero del artículo 225 del código de Bello, que determina que «los hijos continuarán bajo el cuidado personal del padre o madre con quien estén conviviendo» y, en consecuencia, corresponde al otro progenitor el ejercicio de la relación directa y regular. Normalmente, en los casos

1. Hablamos de derecho-deber, pues está integrado por el deber de cuidar, criar, formar, educar y establecer a los hijos e hijas, conducta que conforma un imperativo y prerrogativa de los padres y, al mismo tiempo, un derecho de los NNA, cuyo ejercicio configura el cumplimiento de una obligación (Greeven, 2016: 65-89).

2. Este acuerdo es solemne. Debe constar por escritura pública o acta extendida ante cualquier oficial del Registro Civil, la que debe ser subinscrita al margen de la inscripción de nacimiento dentro de los treinta días subsiguientes a su otorgamiento. 
de separación en Chile, los hijos siguen viviendo con la madre y es el padre el que abandona el hogar común; luego, la madre suele ser la titular del derecho-deber de cuidado personal, mientras que toca al padre el ejercicio del derecho-deber de mantener una relación directa y regular. ${ }^{3}$ En otros términos, la excepción está dada por los casos en que el cuidado personal es ejercido por el padre. Lo indicado será crucial en nuestro trabajo, puesto que partiremos de dicho supuesto: la madre es la titular del cuidado personal y al padre corresponde el ejercicio de la relación directa y regular.

Finalmente, puede discutirse en juicio la titularidad del cuidado personal. Así, en sede de atribución judicial del cuidado personal existen ciertos criterios ${ }^{4}$ en el nuevo artículo 225-2 del Código Civil que orientan la labor del sentenciador (Lahtrop, 2017: 332). De este modo, el mencionado precepto ofrece «un elenco de indicadores que nos acercan a la determinación de qué debe considerarse como el interés del menor. $\mathrm{Su}$ interpretación y aplicación queda, como es lógico, en manos de los tribunales, cuyo margen de actuación será, en todo caso, más restringido».5 En este sentido, el criterio rector para determinar el cuidado personal será el principio del interés superior del niño, el que se construirá por el juez a partir de las reglas que señala el artículo 225-2 del Código Civil.

En suma, si se ha atribuido a un padre de modo convencional, legal o judicial el cuidado personal, corresponderá al otro el derecho-deber de mantener una relación directa y regular con sus hijos e hijas, lo que concuerda con lo prescrito en el artículo

3. Es interesante destacar que las normas reguladoras del cuidado personal fueron modificadas por la Ley 20.680, publicada en el Diario Oficial el 21 de junio de 2013, legislación que incorporó varios cambios, entre los que destaca la derogación de la regla contenida en el artículo 225 del Código Civil que daba preferencia a la madre. El antiguo inciso primero del artículo 225 del Código Civil indicaba: «Si los padres viven separados, a la madre toca el cuidado personal de los hijos». El mismo artículo modificado por la Ley 20.680 dispone en su inciso tercero: «A falta del acuerdo del inciso primero, los hijos continuarán bajo el cuidado personal del padre o madre con quien estén conviviendo». Con todo, la modificación no produjo mayores alteraciones en la práctica, dado que, como hemos señalado, en la gran mayoría de los supuestos de separaciones entre los padres, los NNA continúan viviendo con la madre.

4. Estos criterios pretenden orientar la labor del juez en la atribución del cuidado personal de los NNA, y son los siguientes: la vinculación afectiva entre los padres, personas del entorno familiar y el NNA; la aptitud de los primeros para garantizar el bienestar de los últimos y la posibilidad de procurarles un entorno adecuado, según su edad; la contribución a la mantención del NNA mientras estuvo bajo el cuidado personal del otro padre, pudiendo hacerlo; la actitud de cada uno de los padres para cooperar con el otro, a fin de asegurar la máxima estabilidad del NNA y garantizar la relación directa y regular; la dedicación efectiva que cada uno de los padres procuraba al NNA antes de la separación y, sobre todo, la que pueda seguir desarrollando de acuerdo con sus posibilidades; la opinión del NNA; el resultado de los informes periciales; los acuerdos de los padres; el domicilio de estos; $y$, a modo de cláusula abierta, todo otro antecedente que sea relevante atendido el interés superior del NNA. Véase Lepin (2013: 285-308).

5. Para un mayor análisis de este punto, véase Ravetllat y Pinochet (2015). 
9.3 de la Convención de los Derechos del Niño. Considerando la separación producida entre los padres, la referida relación persigue que el progenitor no custodio no pierda contacto con sus hijos e hijas y que participe activamente en las decisiones relevantes de la vida del NNA (Acuña, 2020: 88); de ahí que se busque el establecimiento de un régimen comunicacional estable y periódico. Lo dicho se vincula con las exigencias emanadas del principio de corresponsabilidad parental, al que nos referiremos en las páginas siguientes.

A propósito del ejercicio del régimen comunicacional, debemos considerar la creciente influencia ejercida por los medios telemáticos. En efecto, los avances tecnológicos han permitido eliminar varios obstáculos causados por las distancias geográficas, posibilitan una mayor "cooperación social» (Coloma, Agüero y Lira, 2021: 113), dotaron de inmediatez a la forma de relacionarnos y posibilitaron un contacto más fluido (Ortíz y Viollier, 2021: 78). Tales avances han tenido un efecto positivo en las familias, en este sentido (como lo han planteado Oliva y Villa, 2014: 17), con referencia a internet, esta «genera espacios de encuentro y de mediación de la comunicación, aportando temas de debate y conversación en el entorno familiar».

El derecho no puede quedar ajeno a esta nueva realidad, por el contrario, debe asumirla y aprovecharla. ${ }^{6}$ En esta senda, resulta claro que las mencionadas innovaciones en las herramientas comunicacionales han tenido un influjo innegable en el modo de relacionarse de los integrantes de las familias, por lo que su correlato jurídico es inevitable teniendo en vista la necesidad de una relación fluida entre padres e hijos e hijas que no comparten el mismo hogar. En breves palabras, la relación entre padre e hijos e hijas no puede quedar aislada de las ventajas derivadas de los medios telemáticos de comunicación.

Existen en el derecho comparado regulaciones relativas al empleo de los medios telemáticos en los regímenes de comunicación entre padres e hijos e hijas, como el Código de Utah y la Ley de Visitas Virtuales de Puerto Rico. ${ }^{7}$ No sucede lo mismo en el derecho chileno, esto es, dicho relevante tema carece de una disciplina expresa en nuestro ordenamiento jurídico.

Teniendo en vista lo indicado en los párrafos precedentes, esta investigación propone analizar la influencia y relevancia que las nuevas formas de comunicación poseen en el ejercicio de la relación directa y regular en el derecho de familia chileno, de modo tal de afirmar que esta no se limita solamente a un contacto físico directo entre padres e hijos e hijas. Todo lo indicado debe entenderse en el contexto de las autori-

6. En idéntico sentido se ha pronunciado la sociología, ciencia social que define familia «como un organismo cultural viviente que evoluciona por adaptación del ambiente. La familia es vista como una institución, que, aunque creada por la sociedad, responde a necesidades naturales» (González, 2009: 513).

7. Véase Código de Utah, título 30, capítulo 3, sección 33, y la Ley de Visitas Virtuales de Puerto Rico del 25 de septiembre de 2012 . 
zaciones para salida al extranjero que posean el carácter de prolongadas o definitivas, sin perjuicio de analizar la incidencia que en la materia ha tenido el covid-19.

\section{Salidas prolongadas o definitivas al extranjero de madres acompañadas de sus hijos e hijas: Corresponsabilidad parental y régimen de comunicación por medios telemáticos}

En esta sección estudiaremos las migraciones que reconocen como protagonistas a los hijos e hijas y a sus madres custodias (Mira y Bastías, 2021: 4). Afirmaremos la relevancia que en la materia posee el principio de corresponsabilidad parental y vincularemos todo lo anterior al ejercicio de la relación directa y regular por medios modernos de comunicación.

\section{Migraciones de madres e hijos e hijas}

La estructura familiar ha variado con respecto a su forma más tradicional constituida por la familia nuclear matrimonial (padre, madre e hijos). En dicho sentido, en la actualidad se reconoce una gran variedad de clases de familia (Arriagada, 2007: 10):

Las personas pueden optar por vivir solas, en parejas sin hijos, en hogares monoparentales, en uniones consensuales, en uniones homoparentales. Se sabe de un creciente número de familias recompuestas (parejas que se unen y traen sus hijos de uniones anteriores y de otros padres), así como de familias a distancia, producto de las migraciones de alguno de sus integrantes, pero cuyo peso se desconoce porque no es posible inferir su magnitud a partir de la información de censos de población y de encuestas de hogares.

Así como han emigrado núcleos familiares completos (padre, madre, hijos e hijas $y$, en ocasiones, otros parientes), en otros casos han salido de las fronteras del territorio chileno solamente algunos integrantes de la familia: en el supuesto que nos interesa, madres junto a sus hijos e hijas. El escenario descrito incide de manera decisiva en el modo de comunicarse de los miembros de las familias, realidad que no ha sido reconocida ni regulada en términos explícitos por el derecho de familia chileno, a lo menos respecto del objeto del presente artículo. En otras palabras, existe una dicotomía entre el modo de ejercicio de la práctica de la relación directa y regular y la disciplina positiva que se ocupa de esta.

Avanzando en la misma senda del párrafo anterior, cada día con mayor frecuencia se observan mujeres que emigran de Chile junto con sus hijos e hijas hacia el extranjero. Lo dicho se vincula con el nuevo rol que la mujer ha asumido en las modernas formas de familia: la mujer como «jefa» de familia. En este sentido, la mujer ha superado la tradicional función que la circunscribía exclusivamente al rol de madre encargada del cuidado de los hijos e hijas y del hogar familiar, permanentemente supe- 
ditada al hombre. Agréguese a lo anterior su inserción en el mercado laboral, lo que ha generado como consecuencia un aumento en el campo de libertad y autonomía de las mujeres. ${ }^{8}$ Considerando lo indicado, no sorprende que la mujer sea protagonista, sola o acompañada de sus hijos e hijas, de movimientos migratorios: esta, al igual que el hombre, es titular del ius peregrinandi.

El derecho internacional no ha sido indiferente al escenario narrado. De este modo, en diversos instrumentos se ha reconocido a todas las personas el derecho a emigrar, entre estos, podemos mencionar la Declaración Universal de los Derechos Humanos (artículo 13) y la Convención Americana de Derechos Humanos (artículo 22). Además, existen textos específicamente dedicados al tema migratorio, como la Convención sobre la Protección de los Trabajadores Migrantes y sus Familiares y la Convención sobre el Estatuto de los Refugiados. A todo lo señalado debe agregarse la Convención sobre la Eliminación de todas las Formas de Discriminación en contra de la Mujer, otro de los instrumentos que le han permitido al sistema internacional de protección de derechos hacerse cargo de la materia en comento. A mayor abundamiento, para aminorar discriminaciones, «desde la década de los noventa la comunidad internacional de derechos humanos comenzó a hacer alusión al enfoque de género y a la importancia de su transversalización» (Herrera, 2020: 14).

En el sistema jurídico chileno, con el transcurso de los años se ha reconocido por parte de la doctrina ${ }^{9} \mathrm{y}$ la jurisprudencia ${ }^{10}$ el derecho de las mujeres madres custodias

8. En dicho proceso influyó «la ideología democrática de igualdad de derechos que comenzó a extenderse junto con los estudios realizados por investigadores feministas (mujeres y hombres), los que hicieron visible la amplitud de los roles de la mujer» (Cebotarev, 2003: 8).

9. En un análisis de la Convención sobre la Eliminación de todas las Formas de Discriminación contra la Mujer, específicamente de su tratamiento de la igualdad, se ha sostenido: «En primer lugar, no debemos perder de vista el concepto de discriminación que la CEDAW nos entrega en su artículo primero. En efecto, esta norma establece que la expresión "discriminación contra la mujer", denotará toda distinción, exclusión o restricción basada en el sexo que tenga por objeto o por resultado menoscabar o anular el reconocimiento, goce o ejercicio por la mujer, de los derechos humanos y las libertades fundamentales en las esferas política, económica, social, cultural y civil o en cualquier otra esfera. Como queda claro, la discriminación contra la mujer no solo se produce cuando existe intención de discriminar sino también cuando, por resultado, se produzca discriminación» (Lathrop, 2010: 165).

10. Así lo ha resuelto la Corte Suprema: «Por otra parte, lo que sí constituye un análisis abstracto o alejado de la realidad concreta de las personas involucradas en esta controversia, es obviar el derecho de la madre que tiene a su cargo el cuidado personal de los niños, a procurar un desarrollo profesional y afectivo que satisfaga sus intereses, contraponiéndolo a lo que puede ser el interés de los hijos. El entendimiento del principio del interés superior debe ser acorde a la evolución social de las familias, lo que implica respetar las individualidades de quienes conforman el núcleo familiar y asumir que la exigencia de una figura ideal de madre que, en cuanto cuidadora de sus hijos, posterga su desarrollo en otras esferas de su vida responde a una concepción estereotipada y que tampoco favorece a los hijos que son objeto de tales cuidados», Corte Suprema, causa rol 42.642-2017, del 28 de abril de 2018, considerando cuarto. 
a emigrar y a desarrollar las diversas facetas que constituyen su personalidad, como los aspectos profesional y sentimental. ${ }^{11}$ A mayor detalle, entendemos que la titularidad del cuidado personal también implica la facultad del progenitor custodio de poder elegir el lugar donde residirán sus hijos e hijas, pues solamente esta manifestación de la prerrogativa del cuidado personal permitiría explicar que en varias ocasiones la jurisprudencia se hubiese pronunciado favorablemente con respecto a la salida al extranjero, incluso sin fecha de retorno, dado que la elección del lugar de residencia sería una especie de irradiación del nombrado derecho-deber. En dicho sentido se ha pronunciado recientemente la Corte Suprema. ${ }^{12}$

Lo recientemente señalado ha generado debate en el derecho comparado y en Chile. Así, en la common law se ha hablado del ne exeat. Lo indicado se fundamenta en el daño que la migración generaría para el NNA en virtud de la lejanía que se produciría respecto de su padre. En el señalado sentido se ha pronunciado Regina Tavares (2016: 271-288) en un trabajo cuyo título es muy decidor: «La guarda de niños no es posesión o propiedad». En Chile también alguna doctrina ha acogido el ne exeat, en efecto, María Rodríguez ha sostenido que «la salida de los niños del país haría difícil o imposible la participación del padre en el cuidado de sus hijos, finalidad que persigue el cuidado personal compartido y el mismo derecho de ne exeat». ${ }^{13}$

Sin perjuicio de esta interesante discusión, es claro que los tribunales chilenos sí aceptan las migraciones definitivas o prolongadas de madres acompañadas de sus hijos e hijas. ${ }^{14}$ Pero, como ya hemos indicado, la legislación civil no ha sido objeto de modificaciones en el sentido indicado, es decir, no regula la realización de la relación directa y regular en los casos de una migración definitiva de una madre titular del cuidado personal acompañada de sus hijos e hijas.

Más precisamente, la regulación de salida al extranjero de los hijos se encuentra regulada en los artículos 49 y 49 bis de la Ley de menores. ${ }^{15}$ En esencia, a falta de au-

11. Teniendo en vista el tenor del artículo 10 de la Constitución de España y la jurisprudencia del Tribunal Constitucional de dicho país, se ha expresado que el principio del libre desarrollo de la personalidad es uno de los fundamentos del orden político y de la paz social, que se vincula con la noción de «autodeterminación consciente y responsable de la propia vida» y que entronca con el valor jurídico «dignidad de la persona». Véase De Verda y Beamonte (2014: 13).

12. Véase la causa rol 24.265-2019, del 26 de mayo de 2020, y la sentencia de la Corte de Apelaciones de Antofagasta, rol 44-2017, del 21 de febrero de 2017.

13. Para profundizar sobre estas ideas, revísese María Rodríguez, «Autorización de los padres para la salida de los menores del país», El Mercurio Legal, 21 de noviembre de 2017, disponible con suscripción en https://bit.ly/3oNWSbM.

14. Revísense las siguientes sentencias, todas de la Corte Suprema, roles: 24.265-2019, del 26 de mayo de 2020; 358-2019, del 20 de abril de 2020; 4.992-2019, del 30 de marzo de 2020; y 477-2019, del 24 de julio de 2019.

15. Publicada en el Diario Oficial el 8 de marzo de 1967. 
torización del padre que ejerce la relación directa y regular, la madre puede solicitar la correspondiente autorización judicial, pero esta debe otorgarse si se cumplen de manera copulativa los siguientes requisitos: debe acreditarse que la salida es beneficiosa para el interés superior del NNA y debe fijarse en la resolución judicial un plazo de duración del permiso. Se advierte que el supuesto de migración definitiva no está regulado y que, en consecuencia, existe una laguna legal - reconocida por la doctrina especializada - que ha sido solucionada aplicando el principio del interés superior del NNA (Etcheberry, 2016: 129-139; Montecinos, 2018: 569-589).

Con todo, como ya lo hemos indicado, y siguiendo a Astudillo (2020: 397-407), en varias oportunidades los tribunales chilenos han concedido autorizaciones para salidas definitivas o prolongadas al extranjero protagonizadas por madres e hijos e hijas. Lo anterior nos lleva a preguntarnos por el modo en que en tales situaciones puede ejercerse la relación directa y regular. La respuesta a esta interrogante pasa por la apreciación de las formas telemáticas de comunicación. Pero un estudio completo del punto requiere pronunciarse sobre el principio de corresponsabilidad parental y el contenido de la relación directa y regular.

\section{La relación directa y regular y su vinculación con el principio de corresponsabilidad parental}

El inciso segundo del artículo 229 del Código Civil establece la siguiente definición de relación directa y regular: «Se entiende por relación directa y regular aquella que propende a que el vínculo familiar entre el padre o madre que no ejerce el cuidado personal y su hijo se mantenga a través de un contacto periódico y estable». Como podrá advertir el lector, la legislación chilena no ha precisado modalidades específicas de realización de la definida relación.

La relación directa y regular es un derecho-deber. Siguiendo en esta parte las explicaciones de Barcia, lo indicado «se traduce en un deber-facultad recíproco o correlativo, de doble titularidad, en cuanto a que el padre no custodio puede exigirlo al menor y el menor también puede exigir al padre custodio y no custodio, su ejecución se centra en la comunicación entre padres e hijos» (Barcia, 2018: 55). ${ }^{16}$ En términos generales, siguiendo a Acuña, la finalidad de la relación directa y regular es propiciar el desarrollo integral del NNA disminuyendo los efectos perniciosos derivados de la ausencia de convivencia habitual con sus progenitores (Acuña, 2017: 416).

En línea con lo anterior, según dispone el inciso cuarto del artículo 229 del Código Civil, a propósito de la relación directa y regular, el juez debe asegurar la mayor

16. En contra, Acuña (2013: 31) ha sostenido que la relación directa y regular no implica un deber recíproco, dado que esta posee alcances diferentes según se la analice desde el punto de vista de los padres o de los hijos. 
participación y corresponsabilidad de los padres en la vida del NNA. Por su parte, de acuerdo a la segunda parte del inciso primero del artículo 224, el principio de corresponsabilidad determina que ambos padres, «vivan juntos o separados, participarán en forma activa, equitativa y permanente en la crianza y educación de sus hijos».

Como lúcidamente lo ha explicado Acuña, y tal como puede advertirse del transcrito texto legal, el principio de corresponsabilidad se encuentra íntimamente ligado con el principio del interés superior del NNA. En efecto, sin considerar a este último, el primero carece de contenido, de este modo, sin desconocer la debida igualdad entre hombres y mujeres, el principio de corresponsabilidad parental debe buscar el logro del mejor interés de los hijos e hijas. ${ }^{17}$

La corresponsabilidad parental aparece como una noción amplia que implica un involucramiento directo y continuo de los padres en las labores de crianza de los NNA, lo que incluye desde el derecho-deber que corresponde a cada padre de definir cómo serán criados sus hijos e hijas y los valores que les transmitirán en un ambiente de cariño, «que al mismo tiempo incentive su desarrollo intelectual, hasta la toma de decisiones sobre su enseñanza, comprendiendo tanto aspectos académicos como los sociales, incluyendo el saber compartir, el ser sociable, respetuoso, honesto y tolerante» (Arancibia y Cornejo, 2014: 303).

Hasta el momento han quedado suficientemente establecidas dos cuestiones: en primer término, la madre custodia puede emigrar al extranjero junto con sus hijos e hijas y, en segundo lugar, esta y el padre que ejerce la relación directa y regular deben cumplir con los requerimientos emanados del principio de corresponsabilidad parental. Lo último es efectivo sea que el NNA viva con su madre en Chile o en el extranjero. En consecuencia, surge la interrogante de cómo conciliar ambas cuestiones. La respuesta se encuentra en un adecuado ejercicio del régimen comunicacional, pero en virtud de la distancia física existente entre padre no custodio e hijos e hijas, lo anterior implica la modificación de la vigente relación directa y regular, de forma tal que este incluya el empleo de los modernos medios de comunicación. Lo último supone superar el tradicional contenido asignado a la relación directa y regular.

17. Basándose en un análisis de textos internacionales relativos a la protección de la infancia y de la adolescencia, Acuña explica que la corresponsabilidad parental exige que ambos padres asuman las responsabilidades correspondientes respecto de sus hijos, «no tanto porque ambos tienen iguales derechos, sino porque así lo demanda el interés superior de los niños». Agrega la nombrada autora que parte de la doctrina chilena ha considerado que es dudosa la autonomía del principio de corresponsabilidad parental, dado que este tiene como fundamento al principio del interés superior del NNA. A mayor detalle, el principio de corresponsabilidad parental sería una de las tantas aplicaciones del principio del interés superior del NNA. Así, concluye Acuña (2013:34) que el principio de corresponsabilidad, aunque está íntimamente vinculado con la igualdad de los padres, apunta esencialmente al interés de los hijos. 


\section{Ampliación del clásico contenido de la relación directa y regular}

Tradicionalmente la forma de ejercicio de la relación directa y regular está constituida por las visitas presenciales físicas, en términos gráficos, «cara a cara». Pero lo anterior ha sido modificado a la luz de los avances que se han producido en el ámbito de las comunicaciones, según explicaremos con mayor detalle en las líneas siguientes.

Efectivamente, como lo han indicado Barrera y Duque (2014: 32), la familia ha sido permeada por «las tecnologías de la información y de la comunicación y, por consiguiente, estas pueden estar modificando hábitos y costumbres de los miembros que componen la unidad familiar». Es sabido que la irrupción de las nuevas tecnologías ha cambiado el modo de interacción entre las personas, y, en consecuencia, es indudable que también repercuten en la familia ${ }^{18} \mathrm{y}$ en la forma en que esta debe ser comprendida en la actualidad. Las nuevas formas de comunicación se han convertido en una de las maneras más comunes de compartir y relacionarse, por tanto, una concepción moderna de familia debe considerarlas como un agregado cultural de nuestros tiempos (Oliva y Villa, 2014: 11-20).

La influencia de los cambios tecnológicos en el régimen comunicacional ha sido reconocida por la doctrina. Como ha sostenido Gómez de la Torre, dicho régimen incluye las comunicaciones por teléfono, cartas, o mediante correos electrónicos, «telecomunicación que no puede ser prohibida o controlada por el padre que ejerce el cuidado personal, salvo por graves y justificadas razones, en atención al interés del hijo» (Gómez de la Torre, 2011: 127). En otros términos, el ejercicio de la relación directa y regular no se limita de manera exclusiva a la comunicación física-directa entre padre, madre e hijos o hijas, sino que bien puede comprender otras formas diversas de relación.

Concretamente, el derecho-deber en comento se ejerce al menos de tres formas distintas: la visita stricto sensu - que alude a una modalidad específica de relación o contacto físico, consistente en que el NNA es frecuentado por el padre en determinadas oportunidades (días y horarios fijados convencional o judicialmente)—; la comunicación indirecta o correspondencia, esto es, comunicación oral o escrita por cualquier medio no presencial, incluidos los informáticos como las redes sociales; y la convivencia o albergue del niño en casa del progenitor no custodio por ciertos períodos.

18. Un punto relevante es el uso de los NNA de internet, uso que bien puede conducir a una verdadera adicción, por lo tanto, en esta materia es fundamental la labor de los padres. Se ha recomendado para tratar adecuadamente lo anterior el establecimiento de un diseño familiar de utilización de internet (en espacios comunes y en horarios previamente definidos); los padres deben educar a sus hijos sobre el uso de internet. Todo lo indicado se basa en la relación afectiva que debe existir entre padres e hijos. Esta carga moral justifica que los padres «tengan mejores posibilidades de anticiparse y prevenir los actos ilícitos o perjudiciales del niño en internet y, de este modo, asegurarse que el niño no sea ni víctima ni agente de actos dañinos» (Rizik, 2019: 456-457). 
Es necesario analizar la historia fidedigna del artículo 229 del Código Civil, puesto que el elemento histórico de interpretación nos permite fundamentar y comprender de mejor manera la admisibilidad de los medios telemáticos a propósito del régimen comunicacional. Originalmente dicho precepto indicaba que la relación directa y regular implicaba, como su denominación lo explicaba, una relación directa, regular y, además, «personal», lo que en definitiva fue modificado llegándose a la redacción actual, puesto que se eliminó el término «personal». La inclusión de este adjetivo en la redacción primigenia del precepto en análisis obedecía a la intención del legislador de lograr una redacción que guardase armonía con lo establecido en la Convención sobre los Derechos del Niño.

Efectivamente, el artículo 9.3 de la nombrada convención consagra el derecho del NNA que ha sido separado de uno o de ambos padres a mantener relaciones personales y un contacto directo con estos de modo regular, salvo si ello es contrario a su propio interés superior. Es decir, se consagra un régimen comunicacional constituido por un contacto personal y directo, sin embargo, debemos tener presente que la referida Convención data de 1989 y han transcurrido más de treinta años desde su adopción, observándose en este periodo evidentes cambios en las sociedades. A nivel global y, específicamente, en las sociedades de América Latina y el Caribe se han producido una serie de «transformaciones emergentes que representan un desafío para la región, entre las cuales cabe mencionar el cambio tecnológico acelerado y sus implicancias para el mundo del trabajo [...] y los cambios en las dinámicas migratorias» (ONU, Cepal y Unicef, 2018).

Lo anterior nos permite sostener que, si bien la idea inicial del legislador chileno al modificar la regulación del régimen comunicacional fue guardar armonía con lo dispuesto expresamente en la Convención sobre los Derechos del Niño, en vistas a otorgar una mejor tutela de los derechos de este, ello no puede implicar desconocer las variaciones que ha experimentado la región (y el mundo) desde la década de los ochenta de la centuria pasada. En este sentido, mal podría emplearse como elemento de interpretación el texto de la nombrada convención para arribar a una conclusión que desconozca los nuevos escenarios planteados por la tecnología a la familia y, por esta vía, afectar el mejor interés del NNA.

Creemos que la eliminación de la palabra «personal» denota una clara intención del legislador chileno en orden a no circunscribir la relación directa y regular a las visitas físicas, todo esto conteste con las aludidas transformaciones en las formas de comunicación. En este sentido expuso el encargado de protección legal de Unicef en el Congreso de Chile, quien a propósito de la discusión en particular del artículo 229 del Código Civil dijo que el uso del adjetivo «personal, [es una] cuestión discutible, pues hay formas de relación directa y regular que no presuponen el contacto personal, como, por ejemplo, aquellas derivadas de las nuevas tecnologías. Es el caso de las llamadas de teléfono, Skype, etcétera». Agregó el mencionado encargado «que una 
definición de relación directa y regular que agregue el carácter de personal puede importar afectar el régimen de relación directa y regular en estos otros casos». ${ }^{19}$

En la correspondiente discusión parlamentaria se consideró la opinión de algunos académicos de Derecho Civil, como Lahtrop, quien hizo presente que la palabra personal es del «todo inconveniente pues restringe esta función solo a la visita en sentido estricto, cara a cara, desechando la posibilidad de algún otro medio de comunicación electrónico o telefónico, como es la tendencia actual avalada por la jurisprudencia». En el mismo sentido opinó Veloso en el segundo trámite constitucional, esto es, en el Senado, quien instó a tener presente las «circunstancias tales como las tecnologías actuales de comunicación y el hecho de que la residencia de los padres puede encontrarse en lugares y países distintos. Por lo anterior, sugirió que «las palabras que se utilicen para regular este punto no sean restrictivas». Finalmente, la jueza Negroni, también en la discusión parlamentaria, sostuvo que «incluir el término "personal" podría significar, según el juicio de muchos magistrados, una restricción a la relación directa y regular». ${ }^{20}$

En definitiva, creemos que la decisión por parte del juez de autorizar la salida fuera del país de una madre con su hijo o hija de manera prolongada o definitiva no representa necesariamente una confrontación con el derecho-deber de mantener una relación directa y regular. Lo señalado, puesto que el propio artículo 229 del Código Civil señala que la relación directa y regular debe propender a un «vínculo periódico y estable», lo que, en nuestra opinión, se cumple en la mayoría de las sentencias pronunciadas sobre el particular por los tribunales que han regulado el régimen de relación directa y regular, atendiendo la edad del niño y haciendo mención a los medios tecnológicos que puedan contribuir a la realización de una comunicación que cumpla con las características indicadas en el citado precepto legal. Muestra de lo anterior, es la sentencia de la Corte Suprema del 26 de febrero de 2018:

Que, finalmente, atendido lo expuesto por los informes periciales psicológicos y con el fin que el padre adquiera mayor conocimiento y fluidez en el ejercicio de la parentalidad, se estima beneficioso para el niño que sostengan contacto semanal, preferentemente los fines de semana, vía Skype o por otro medio tecnológico que acuerden las partes en su sustitución, así como que la madre remita fotografías e informes acerca del desarrollo físico, psicológico y educacional del niño en forma mensual. ${ }^{21}$

Mismo criterio ha sido aplicado en reiteradas ocasiones en diversas sentencias de los tribunales chilenos. ${ }^{22}$ Por todo lo indicado, queda claro que el contenido de la

19. Historia de la Ley 20.68o, p. 291, disponible en https://bit.ly/3Fwocza.

20. Véase la historia de la Ley 20.68o, pp. 311, 443 y 498, disponible en https://bit.ly/3Fwocza.

21. Corte Suprema, causa rol 40.678-2017, del 26 de febrero de 2018, considerando cuarto.

22. Véase, entre otras, las siguientes sentencias: Corte Suprema; causa rol 70.160-2016, del 18 de abril 
relación directa y regular no debe circunscribirse exclusivamente a las visitas físicas. Esta interpretación es respetuosa del principio del interés superior del NNA, dado que contribuye al mejor bienestar de este que el derecho a compartir con el padre no custodio se cumpla de todas las formas posibles, empleando, según el caso lo amerite, las ventajas que ofrecen los avances de la ciencia y de la tecnología. En esta senda, es contrario a la realidad desconocer el escenario actual caracterizado por el surgimiento y auge de las redes sociales como Facebook, Instagram o Tiktok:

Sumado a los medios de comunicación social como Twitter o Flickr, unido a las posibilidades que ofrecen los nuevos dispositivos móviles para acceder a estas herramientas y mantener de forma permanente el contacto con otras personas, están promoviendo la comunicación entre diferentes miembros de la familia. También, están permitiendo la gestión del "yo" (cuentas de correo y de redes sociales), de modo que se están viendo cubiertas gran parte de las vías de comunicación entre los diferentes miembros del hogar, posibilitando que esta comunicación tenga un carácter instantáneo y pertinente (Hernández, López y Sánchez, 2014: 38).

Sin perjuicio de lo indicado precedentemente, entendemos que en los supuestos de salidas prolongadas o definitivas al extranjero debe darse una relación de complementariedad entre las formas telemáticas y las visitas presenciales. En dicho sentido, de ningún modo planteamos que las formas telemáticas deben imposibilitar los encuentros físicos, pues creemos que los medios tecnológicos de comunicación deben ser entendidos, insistimos, como un complemento de las visitas físicas. En suma, en los casos indicados, el régimen comunicacional puede consistir en un sistema mixto que contemple tanto las visitas virtuales como el contacto personal.

Lo anterior se justifica, dado que no podemos pasar por alto la naturaleza jurídica de la relación directa y regular: es un deber, pero, al mismo tiempo, es un derecho para el NNA y para el padre no custodio. Centrándonos en el último, este, salvo situaciones muy excepcionales, no puede verse perjudicado por la sustitución completa del modo en que se materializaba el derecho-deber en comento, debiéndose, a nuestro juicio, propender a un equilibrio. Dicho equilibrio, en un contexto de migración al extranjero, solamente se logra entendiendo que los contactos telemáticos son un coadyuvante de gran utilidad de la visita y convivencia física, la que se verá restringida por el cambio de circunstancias al que hemos aludido.

Así lo ha estimado recientemente la Corte Suprema, al corregir una sentencia de grado por haber omitido lo concerniente al modo en que debía efectuarse la relación directa y regular. Expresamente se indicó en el considerando octavo:

de 2017; causa rol. 36.593-2015, del 21 de abril de 2016; causa rol 8.728-2012, del 25 de marzo de 2013; Corte Apelaciones de Santiago, causa rol 318-2016, del 11 de abril de 2016; y Corte Apelaciones de Puerto Montt, causa rol 197-2013, del 21 de agosto de 2014. 
Resulta perentorio concluir que la sentencia impugnada ha infringido su mandato, y que influyó en lo dispositivo del fallo, al haber omitido salvaguardar también el derecho-deber del padre para mantener con la niña F. la relación directa y regular ya existente, de manera compatible con su viaje al extranjero al cuidado de la madre, mediante un debido pronunciamiento sobre el régimen comunicacional de la hija con su padre durante su estada en ultramar.

Se agregó en el considerando segundo:

Por estas consideraciones, se confirma la sentencia apelada de seis de agosto de dos mil dieciocho, con declaración de que la madre de la niña [...] debe permitir y facilitar su viaje de retorno transitorio al país, por diez días corridos al cabo de los primeros seis meses de su estadía en la República de Francia, así como permitir y facilitar el contacto diario de la niña con su progenitor por Skype u otro sistema de videoconferencia durante todo su periodo de ausencia del territorio nacional. ${ }^{23}$

Todo parece indicar que los medios telemáticos de comunicación aumentarán en su calidad y accesibilidad y, por tanto, en su incidencia en nuestra sociedad, incluyendo, desde luego, a la familia, por lo que podemos afirmar que admitir la relevancia de tales medios en el régimen comunicacional entre padre e hijos e hijas es una aplicación del principio de realidad. El triste panorama impuesto por el covid-19 ha reafirmado lo anterior, según indicaremos a continuación.

\section{El impacto del covid-19}

Al momento de escribir este artículo, la humanidad sufre los perniciosos efectos derivados de la pandemia por covid-19. Dicha enfermedad ha trastocado los cimientos de nuestras sociedades, por lo que su influencia en el ámbito jurídico es innegable. ${ }^{24}$ El derecho de familia ha debido adaptarse a lo anterior, reaccionando ante las nuevas realidades y desafíos generados por el covid-19. ${ }^{25}$

Centrándonos en el objeto de nuestro interés, se ha reforzado la utilización de los medios telemáticos como alternativas válidas en lo relativo al ejercicio de la relación directa y regular. Efectivamente, la lucha en contra del aumento de los contagios por coronavirus ha impactado en la referida relación, dado que las autoridades sanitarias

\footnotetext{
23. Corte Suprema, causa rol 4.992-2019, del 30 de marzo de 2020.

24. Así, por ejemplo, en el derecho contractual se ha producido un resurgimiento de estudios relativos a temas tales como la teoría de la imprevisión o de la excesiva onerosidad sobreviniente; el caso fortuito o fuerza mayor; y, en términos más generales, el impacto del covid-19 en el incumplimiento de las obligaciones emanadas de un contrato. Véase Varsi, Rosenvald y Torres (2020: 29-36), Isler (2020: 92-124) y Tapia (2020).

25. En este sentido, recomendamos la lectura de Daniela Horvitz, «Los procedimientos de familia en Chile y el covid-19», Diario Jurídico, 18 de mayo de 2020, disponible en https://bit.ly/3xcQI9e.
} 
han recomendado medidas de aislamiento social (Broche, Fernández y Reyes, 2020: 4) que han llegado incluso a los confinamientos voluntarios o forzados en nuestros respectivos hogares.

En el primero de los supuestos, es decir, en los enclaustramientos de índole voluntaria, surge en las madres titulares del cuidado personal la natural y comprensible (e inevitable, podríamos agregar) preocupación de limitar, en la mayor medida posible, el contacto de sus hijos e hijas con otras personas. Es viable que, dentro de lo anterior, se incluya al padre que ejerce una relación directa y regular, situación que tiene el potencial de causar un conflicto familiar de entidad. Adherimos a la posición que sostiene que, adoptando todos los resguardos sanitarios que resulten adecuados, el padre puede continuar visitando presencialmente a su hijo e hija. En otros términos, la actual crisis sanitaria no debe entenderse como una causal que habilita a la madre para suspender o modificar unilateralmente el ejercicio de la vigente relación directa y regular. ${ }^{26}$

Sin perjuicio de lo anterior, la prudencia y la consideración del principio del interés superior del NNA, aspectos que deben inspirar la corresponsabilidad parental, pueden aconsejar a los padres en el sentido de disminuir la frecuencia de las visitas presenciales y combinarlas con visitas telemáticas. En otros términos, a lo menos temporalmente, $y$ teniendo en vista la evolución que experimente la pandemia, se ha observado un auge voluntario del empleo de medios telemáticos a propósito de relaciones directas y regulares originalmente reguladas exclusivamente sobre la base de regímenes presenciales.

Más complejo es el escenario planteado por las medidas de restricción de la libertad desplazamiento dictadas por las autoridades competentes, las denominadas «cuarentenas», que, inicialmente, poseían una duración de diez días y podían ser renovadas las veces que el Ministerio de Salud estimase conveniente, pero que luego pasaron a ser indefinidas. Una de sus consecuencias fundamentales es que, en principio, las personas no pueden salir de sus hogares a menos que cuenten con permisos especiales o salvoconductos.

En concreto, nos interesa el llamado permiso temporal individual-retorno del menor o adolescente al hogar del tutelar (PTIR). Como su denominación lo indica, dicho permiso tiene por objeto regresar al NNA al hogar en que habita con quien

26. El punto ha sido discutido. En Argentina, el Quinto Juzgado de Familia de La Plata, en sentencia del 27 de marzo de 2020, dispuso que el régimen comunicacional «se efectivice por medio de videollamadas, como mínimo una vez al día, debiendo ambas partes extremar los esfuerzos, flexibilidad y comprensión que la presente emergencia impone en virtud de su responsabilidad que como progenitores les cabe en la posibilidad de que el niño disfrute del ejercicio de sus derechos en forma plena, atendiendo a las circunstancias y respetando a su vez los tiempos de su hijo». Esta sentencia ha sido comentada por Donato y otros (2020: 2). 
ejerce a su respecto el cuidado personal. En consecuencia, permite la continuidad del régimen de relación directa y regular existente con anterioridad a la pandemia, en su modalidad de visitas presenciales.

A mayor detalle, el PTIR, solicitado en línea, tiene una breve duración de dos horas, espacio de tiempo que debería permitir transportar al NNA desde el lugar en el que se realiza la relación directa y regular al hogar del padre custodio. Esto es, el permiso en comento está pensado para aquellos casos en que los padres y el NNA habitan en una misma ciudad o en localidades cercanas. ${ }^{27}$.

Es interesante resaltar que el PTIR originalmente no formaba parte del catálogo de permisos, sino que fue creado una vez ya vigentes varias medidas adoptadas en el contexto de la pandemia: el Poder Ejecutivo ha debido intentar conciliar el derecho a la salud con el derecho de los padres de visitar a sus hijos e hijas. En efecto, en principio, el Gobierno de Chile optó por la suspensión de los regímenes de relación directa y regular, disponiéndose la recuperación de las visitas no realizadas una vez cesada la emergencia sanitaria. Se trata de un punto que ha sido objeto de discusiones en el derecho comparado. ${ }^{28}$

Con todo, existen situaciones en la que por disposición de la autoridad sanitaria es imposible la realización de una visita «cara a cara». En dicho sentido, el permiso en análisis posee dos limitaciones fundamentadas en la intención de controlar la pandemia: en primer término, la existencia de «toque de queda» $y$, en segundo lugar, el caso de personas sujetas a restricción sanitaria.

Con respecto a la primera limitación, el PTIR no será válido durante los horarios de duración de los toques de queda, es decir, desde las diez de la noche hasta las cinco de la mañana del día siguiente. Lo anterior debido a que mediante el Decreto 104 del 18 de marzo de 2020, el presidente de la república decretó en todo el territorio de Chile el estado constitucional de catástrofe por causa de calamidad pública. Dicha situación de anormalidad constitucional, en conformidad a lo prescrito en el artículo $41^{29}$ y en el inciso tercero del artículo 43 de la Constitución Política, faculta al Poder

27. Además, el PTIR permite registrar hasta cuatro NNA. Véase https://bit.ly/3csFzYc.

28. En España se ha sostenido lo siguiente: «No vale la máxima, primero está la salud de los menores que el régimen de visitas, porque garantizar la salud de los menores tanto por el progenitor custodio como por el no custodio está en un mismo plano de igualdad. Nadie puede garantizar que un menor no se va a contagiar por estar en el domicilio materno, ni que se va a contagiar si se traslada al domicilio del padre. Observando todas las recomendaciones del Ministerio de Sanidad, el contagio no debería producirse. Lo que sí debe preocupar a los padres es el nivel de exposición del menor, que debe ser el mínimo, especialmente si este tiene alguna patología que suponga a un mayor riesgo a los efectos del virus». Véase Antonio Pérez, «Custodia, visitas y otras medidas en tiempos de coronavirus», Elderecho. com, 6 de mayo de 2020, disponible en https://bit.ly/3 $\mathrm{HO}_{310 \mathrm{C}}$.

29. Según el inciso final de la citada norma: «Declarado el estado de catástrofe, las zonas respectivas quedarán bajo la dependencia inmediata del jefe de la defensa nacional que designe el presidente de la 
Ejecutivo para restringir el derecho de locomoción y el derecho de reunión, entre otras medidas (Ríos, 2002: 251-282; Pfeffer, 2002: 223-250; y Ricci, 2010: 219-231). Con todo, tengamos presente que, salvo los casos en que el régimen de visitas incluya pernoctación en el hogar del progenitor no custodio, en los indicados horarios del toque de queda lo usual es que el NNA se encuentra en el domicilio de la madre (o del padre) encargado de su cuidado personal.

A propósito de la segunda limitación, no podrán solicitar o tramitar el PTIR, ni ningún otro tipo de permiso o de salvoconducto, aquellas personas que se encuentren sometidas a alguna medida de restricción sanitaria que implique aislamiento o cuarentena, ello por ser pacientes con diagnóstico de covid-19 confirmado, por encontrarse en espera de resultados de exámenes médicos relativos a la misma enfermedad o por provenir de algún país extranjero.

De acuerdo a la misma línea de razonamiento, en el evento en que el padre titular del derecho-deber de mantener una relación directa y regular, o el hijo o hija, hubiese contraído covid-19, resulta claro que en dicho supuesto se ha configurado una causal que justifica la suspensión de las visitas presenciales. Por lo tanto, una vez desaparecida la aludida causal, esto es, al ser vencida la enfermedad, deberá procederse a la recuperación de las visitas que no pudieron efectuarse. En este sentido se ha pronunciado Gonzalo Muñoz en España:

Lo expuesto cobraría relevancia si el progenitor con derecho de visitas hubiese contraído la enfermedad, lo que nos llevaría, lógicamente, a una restricción del aludido derecho hasta que la superase, compensando posteriormente el tiempo no disfrutado. Del mismo modo, parece conveniente que si el progenitor custodio o uno de los progenitores, en caso de custodia compartida, tuviese el virus debería tener lugar un cambio temporal de la custodia, más aún si se produce el ingreso hospitalario. ${ }^{30}$

En definitiva, a propósito de las dos limitaciones explicadas, y siempre teniendo en vista el particular contexto creado por la pandemia por covid-19, con el objetivo de mantener un sistema de comunicación periódico y fluido entre el padre que ejerce la relación directa y regular y el hijo e hija, es necesario acudir a las formas telemáticas de comunicación y reconocer su utilidad. En otros términos, en un contexto de crisis sanitaria mundial, las nuevas tecnologías han contribuido a una adecuada observancia de los requerimientos emanados de los principios de corresponsabilidad parental y del interés superior del NNA.

república. Éste asumirá la dirección y supervigilancia de su jurisdicción con las atribuciones y deberes que la ley señale».

30. Véase «El régimen de visitas en tiempo de epidemia: Los criterios judiciales a raíz del covid-19», Boletín Oficial del Instituto de Derecho Iberoamericano, 19 de mayo de 2020, disponible en https://bit. ly/3kVzw2S. 
Lo indicado nos permite marcar un contrapunto con lo sucedido en épocas pasadas a propósito de otras epidemias que han afectado a la humanidad. Anteriormente, con la esperanza de salvar la vida se intentaba romper de un modo absoluto todo contacto con otras personas (Ledermann, 2003: 15), incluidos los parientes más cercanos de la propia familia, lo que motivaba el cese de toda forma de comunicación. Probablemente, la pandemia que mejor ilustra aquello es la llamada "peste negra», «peste bubónica» o «muerte negra», entre otras denominaciones (Sánchez-Davis, 2008: 133-135); la peste por antonomasia (Martínez, 2008: 5-13). A mayor detalle: los padres y madres abandonaban a sus hijos, lo mismo hacían los maridos respecto de sus mujeres, o viceversa; desde luego, los miembros de una familia no se visitaban entre sí y dicha situación de aislamiento no era alterada ni siquiera por la muerte de seres queridos. Estas dantescas consecuencias provocadas por la peste negra en el ámbito de las relaciones de familia fueron brillantemente narrados por Boccaccio. ${ }^{31}$

Centrándonos en los efectos provocados por las enfermedades en las relaciones familiares, pareciera claro que, no obstante los innegables efectos negativos causados por el covid-19, los adelantos en la salud y el surgimiento de las modernas formas de comunicación, entre otros aspectos, han impedido que escenarios de completa desintegración e incomunicación familiar, como el recientemente descrito, se repitan en la actualidad.

En definitiva, podrá advertir el lector que en un escenario que incluye las limitaciones analizadas (toque de queda y la situación de personas sujetas a restricción sanitaria), los padres y sus hijos e hijas seguramente habitan en el mismo país y, eventualmente, en la misma ciudad. En consecuencia, la conveniencia de la realización del régimen comunicacional por medios telemáticos ha sido demostrada sin necesidad de que los protagonistas de la misma residan en diversos países (o en distintas ciudades). Por lo indicado, tales medios han ganado mayor presencia en el ejercicio práctico de la relación directa y regular. Lo dicho nos conduce a una interrogante final: ¿disminuirá la relevancia de las formas telemáticas a propósito de la relación directa y regular una vez controlada la pandemia del covid-19? Sobre este punto nos pronunciaremos a continuación.

31. «De más está decir que cada ciudadano rechazaba al otro, y que casi ningún vecino se preocupaba de los demás, y que la propia familia no se visitaba, por lo menos asiduamente. Esto era resultado del espanto producido por aquella enfermedad; el hermano abandonaba al hermano, el tío al sobrino, la hermana al hermano, y a menudo la mujer al marido; y (lo que es más grave, y casi increíble) los padres y las madres procuraban no visitar ni atender a los hijos, como si no fuesen suyos» (Boccaccio, 2009: 15). 


\section{Consideraciones finales: Hacia una mayor y más consciente utilización de las formas modernas de comunicación en la relación directa y regular}

En este trabajo hemos aludido a los avances que tanto la ciencia como la tecnología han provocado en el ámbito de las formas de comunicación. Todo parece augurar que dichos avances continuarán en los próximos años (Barrios, Díaz y Guerra, 2020: 82), por lo que en el futuro tendremos la posibilidad de acceder a mejores y más eficaces medios telemáticos de comunicación. Siguiendo a Díaz, Pérez y Florido, el gran desarrollo que se ha producido en el campo de las telecomunicaciones y de la informática, la llamada «revolución cibernética», producida especialmente desde la segunda mitad de la centuria pasada, lo que incluye la creación y el auge de internet, necesariamente continuará repercutiendo en todos los ámbitos de nuestras vidas. Expresamente indican los nombrados autores que «el impacto de la digitalización en la sociedad es evidente y cada vez más amplio» (2011: 82-83).

El derecho debe considerar lo anterior. Desde antes de la pandemia por covid-19 las modernas formas de comunicación ya habían permeabilizado el sistema jurídico. Para justificar lo indicado, basta con pensar en las transmisiones en vivo, por televisión o internet, de los juicios que han suscitado un mayor interés social; las notificaciones electrónicas; los registros en audio de las actuaciones judiciales; y en la posibilidad de producir un determinado medio de prueba mediante grabaciones o por el sistema de videoconferencia, lo que ha permitido a Claudia Castro hablar de «prueba electrónica».$^{32}$ Súmese a ello que los masivos contagios por coronavirus han forzado la aplicación de nuevas reglas para la correcta realización de juicios: el teletrabajo ha debido ser implementado por el Poder Judicial. ${ }^{33}$

En el caso del derecho de familia, además de lo señalado en el párrafo precedente, también antes de la aparición del covid-19 podían observarse manifestaciones de la influencia de los medios modernos de comunicación. En dicho sentido, tengamos en vista lo siguiente: la relevancia que han adquirido las denominadas salas Gesell, que contribuyen al respeto de la opinión de los NNA y que están dotadas con el pertinente material de soporte informático de audio y de video; ${ }^{34} \mathrm{y}$, según hemos indicado en páginas anteriores, la realización de la relación directa y regular telemáticamente

32. Con dicha expresión se alude a los medios telemáticos que permiten la reproducción de imágenes, sonidos y datos (Castro, 2015: 769).

33. En este sentido, véase el auto acordado de la Corte Suprema del 18 de marzo de 2020, que regula el teletrabajo y el uso de videoconferencia en el Poder Judicial.

34. Estas salas cuentan con un vidrio oscurecido que las divide en dos espacios. En una parte el NNA puede expresarse ante la presencia de jueces, psicólogos y asistentes sociales, y en la otra, trabaja el personal técnico especialmente calificado para registrar en audio y en video lo sucedido y explicitado durante el proceso de comunicación realizado entre el NNA y las personas mencionadas (Carretta, 2018: 119). 
en los supuestos de autorizaciones judiciales para salidas prolongadas o definitivas al extranjero.

Agréguese a lo señalado la adopción de medidas especiales directamente relacionadas a los efectos de la pandemia. Así, el Estado ha debido reaccionar ante los desafíos y dificultades que ha planteado la situación de crisis sanitaria. Con lo último, nos referimos en concreto a las soluciones colaborativas en las medidas de protección, a los permisos de salida para NNA que padecen de un trastorno del espectro autista (TEA) y al uso de formas telemáticas de comunicación para conocer la opinión del NNA.

Con respecto a lo primero, durante la pandemia se ha verificado un auge en la iniciativa oficiosa judicial tendiente al logro de soluciones colaborativas con las que se pone fin a los procedimientos de medidas de protección. Específicamente, dichos procedimientos surgen ante la amenaza o efectiva vulneración en contra de los NNA. Teniendo en vista el principio del interés superior del NNA, con anterioridad a la sentencia el juez puede — según disposición del inciso primero del artículo 75 de la Ley 19.968, ${ }^{35}$ disciplina que creó los tribunales de familia - procurar «que las partes acuerden la forma más conducente a la resolución de la situación que afecta al niño, niña o adolescente».

Lo interesante para nuestro estudio radica en que mediante llamadas telefónicas o por otros medios modernos de comunicación, los tribunales de familia se han contactado con mayor frecuencia con las partes del procedimiento en comento, con el fin de lograr una solución colaborativa. Lo narrado presenta la clara ventaja de evitar la concurrencia de las partes, entre las que se incluye el NNA y los padres o las personas que detentan la custodia de estos, a dependencias de los tribunales de justicia y, como consecuencia de ello, la eliminación del riesgo de contagio derivado de tales desplazamientos. ${ }^{36}$ Se trata de un ejemplo en que la crisis sanitaria y las formas telemáticas de comunicación, sumadas al buen criterio de los sentenciadores, confluyen en la construcción del mejor interés del NNA.

A propósito de lo segundo, los períodos de enclaustramiento forzado en los hogares afectan de un modo particular a los NNA que presentan algún TEA. En efecto, si las medidas restrictivas de la libertad de desplazamiento y de reunión dispuestas por la autoridad inciden negativamente en el plano psicológico de todas las personas que deben respetarlas, rápidamente podremos comprender que de especial entidad serán sus efectos en los NNA y, particularmente, en los que presenten algún grado de TEA. Sin ánimo de agotar el punto, algunas de las características propias de los NNA

35. Publicada en el Diario Oficial el 30 de agosto de 2004.

36. Usualmente se decreta la apertura de una medida de protección, o "causas $\mathrm{P}$ », ante la ocurrencia de episodios de violencia intrafamiliar, desnutrición, abandono, abusos sexuales y consumo excesivo de alcohol o de sustancias estupefacientes. 
con un TEA pueden agudizarse en situaciones de estrés y de angustia, como las que pueden causar las cuarentenas. Así, siguiendo a Cala, Licourt y Cabrera (2015: 158), pueden aumentar en su intensidad las deficiencias cualitativas en el plano de la interacción social, las falencias de entidad en las habilidades de comunicación, los comportamientos repetitivos y estereotipados; y exacerbarse la atención brindada a un catálogo limitado de intereses y actividades.

Considerando lo señalado, es positiva la creación del permiso temporal individual-salida de personas con espectro autista u otra discapacidad mental, dispuesto por el Poder Ejecutivo. Efectivamente, el citado permiso posibilita que el NNA que tiene un TEA, adoptándose las correspondientes medidas de prevención, pueda salir de su hogar acompañado por su cuidador o por un acompañante, por dos horas. Dichos permisos son solicitados aprovechando los avances de las comunicaciones: debe llenarse un formulario en internet y, en caso de acogerse lo pedido, el permiso es enviado al correo electrónico del solicitante. Se trata de otra medida concreta asociada a la pandemia que hace uso de los avances en la tecnología de las comunicaciones que implica progresar en la senda del mejor interés del NNA y que busca compatibilizar el interés social consistente en controlar la propagación del covid-19 con las necesidades especiales de los NNA con un TEA. ${ }^{37}$

Finalmente, es interesante destacar que las nuevas tecnologías de comunicación, en el contexto del covid-19, son aplicadas para conocer cuál es la opinión del NNA. Ejemplo de esto es que actualmente los jueces de familia recurren a entrevistas remotas mediante videollamadas, como puede apreciarse, entre otras sentencias, en la dictada en el juicio rol Interno Tribunal C 597-2020, pronunciada por el Tribunal de Familia de Iquique, respecto de un niño boliviano que deseaba viajar, acompañado de su madre, a Bolivia.

Todo el contexto indicado en las líneas anteriores nos permite afirmar que el auge que han tenido las formas virtuales de realización de la relación directa y regular no cesará junto con la pandemia por covid-19. Más bien, debido a esta última ha operado un reforzamiento en la toma de conciencia, por parte de los operadores jurídicos, de la necesidad y utilidad que, para los efectos que estudiamos y en otras instancias, como las recientemente indicadas, presentan las modernas formas de comunicación: se trata de una manifestación de un fenómeno de mayor amplitud apreciable en distintos ámbitos..$^{38}$

La nueva realidad impuesta por el covid-19 ha acreditado de manera irrefragable

37. Para un mayor análisis de este punto, revísese Mondaca (2021).

38. Lo mismo puede afirmarse respecto de otras actividades, como el trabajo, la medicina y la docencia. Con respecto a la última, en dicha área se ha generado una renovada valoración de las clases, evaluaciones y actividades asincrónicas realizadas o guiadas mediante diversas plataformas en línea: Zoom, Webex, Meet, entre otras. 
la utilidad de la realización de la relación directa y regular mediante medios telemáticos. Súmese a lo señalado que hemos podido advertir que lo indicado es efectivo no solamente respecto de los casos en que padres e hijos e hijas viven en ciudades pertenecientes a diversas naciones, o en lugares distintos pero ubicados dentro de un mismo país, sino que en aquellos en que los padres y el NNA residen en la misma ciudad. De este modo, las modernas formas de comunicación han visto afianzada su inclusión como una alternativa de modalidad de ejercicio de un régimen comunicacional entre padres e hijos e hijas.

En definitiva, la probada relevancia, eficacia y utilidad de los modernos medios de comunicación en el contexto de la relación directa y regular permitirá enfrentar de mejor manera futuros desafíos para la humanidad, como nuevas pandemias o eventos de igual o de mayor entidad. En pocas palabras, la realidad ha colaborado en la adopción del uso de los nombrados medios de comunicación.

Quizás ha llegado el momento, siguiendo el sendero de regulaciones comparadas, de disciplinar en el derecho positivo chileno las modernas formas telemáticas a propósito de la relación directa y regular. Con ello se reconocería el modo en que en muchos casos se practica esta relación, se respetaría la intención del legislador al modificar el artículo 229 del Código Civil y se acogerían los planteamientos de la doctrina y de la jurisprudencia.

\section{Conclusiones}

Los avances de la ciencia y de la tecnología han permitido el desarrollo de comunicaciones telemáticas que, con el devenir de los años, mejoran su calidad y accesibilidad. Ello debe ser asumido y aprovechado por el ordenamiento jurídico. Así, en las migraciones de las madres al extranjero acompañadas de sus hijos e hijas, los medios telemáticos surgen como una opción válida para efectos de mantener una comunicación entre los NNA y el padre que continúa residiendo en Chile, contribuyendo al cumplimiento de los principios de corresponsabilidad parental y del interés superior del NNA.

Consideremos, además, que los efectos producidos por la pandemia por covid-19 han evidenciado la importancia de las modernas formas de comunicación en el mantenimiento de la relación directa y regular.

En definitiva, el reconocimiento de las formas modernas de comunicación no desaparecerá una vez vencida la pandemia que nos afecta. Por el contrario, consideramos que el covid-19 ha reforzado en los operadores jurídicos la convicción de la necesidad y utilidad de los medios telemáticos para la justicia de familia en general y, particularmente, en el desarrollo de las relaciones entre padres e hijos. 


\section{Referencias}

ACUÑA, Marcela (2013). «El principio de corresponsabilidad parental». Revista de Derecho (Universidad Católica del Norte), 20 (2): 21-59. Disponible en https://bit. ly/3qUpmna.

-. (2020) «Contenido esencial del derecho-deber de cuidado personal de los hijos». Revista de Derecho (Universidad Austral de Chile), 33 (1): 75-95. DOI: 10.4067/ So718-09502020000100075.

-. (2017). «Modificación del cuidado personal de los hijos por obstaculizar el ejercicio del derecho de relación directa y regular». En Rodrigo Momberg, Alexis Mondaca, Daniela Jarufe y Cristian Aedo (coordinadores), Aportaciones adicionales a nuevos horizontes en el Derecho Privado (pp. 411-432). Valparaíso: Ediciones Pontificia Universidad Católica de Valparaíso.

Arancibia, María y Pablo Cornejo (2014). «El Derecho de familia en Chile. Evolución y nuevos desafíos». Ius et Praxis, 20 (1): 279-318. DOI: 10.4067/ s0718-00122014000100011.

Arriagada, Irma (2007). «Familias latinoamericanas: cambiantes, diversas y desiguales». Papeles de Población, 13 (53): 9-22. Disponible en https://bit.ly/3EdFzgS.

Astudillo, Constanza (2020). «Criterios jurisprudenciales para fundamentar la autorización para salir del país y su relación con el principio de interés superior del niño». Revista de Derecho Privado, 39: 397-407. DOI: 10.18601/01234366.n39.16.

BARCIA, Rodrigo (2018). «Determinación del cuidado de la relación directa y regular en Chile». Revista de la Facultad de Derecho y Ciencias Políticas, 48 (128): 49-72. DOI: 10.18566/rfdcp.v48n128.a02.

BARrera, Dagoberto y Luz Duque (2014). «Familia e internet: consideraciones sobre una relación dinámica». Revista Virtual Universidad Católica del Norte, 41: 30-44. Disponible en https://bit.ly/3HDDZRv.

BARrios, Hernando, Vianney Díaz y Yolanda Guerra (2020). «Subjetividades e inteligencia artificial: desafíos para lo humano». Veritas, 47: 81-107. Disponible en https://bit.ly/3×5XY6B.

Boccaccio, Giovanni (2008). El Decamerón. Disponible en https://bit.ly/3oDOYlq. Broche, Yunier, Evelyn Fernández y Darlyn Reyes (2020). «Consecuencias psicológicas de la cuarentena y el aislamiento social durante la pandemia de covid-19». Revista Cubana de Salud Pública, 46: 1-14. Disponible en https://bit.ly/3FwxUo7.

Cala, Odilkys, Deysi Licourt y Niurka Cabrera (2015). «Autismo: Un acercamiento hacia el diagnóstico y la genética». Revista de Ciencias Médicas de Pinar del Río, 19 (1): 157-178. Disponible en https://bit.ly/3EggvAN.

Carretta, Francesco (2018). «Luces y sombras de las cámaras Gesell en la justicia de familia chilena: Estudio a partir de un análisis empírico». Revista CES Derecho, 9 (1): 118-142. DOI: 10.21615/cesder.9.1.7. 
Castro, Claudia (2015). «Las tecnologías de la información y la comunicación (TIC) en el derecho procesal civil hondureño». Revista Chilena de Derecho, 43 (2): 759782. DOI: $10.4067 /$ So718-34372016000200018.

Cebotarev, Nora (2003). «Familia, Socialización y nueva paternidad». Revista Latinoamericana de Ciencias Sociales, Niñez y Juventud, 1 (2): 1-21. Disponible en https://bit.ly/3J4dmpM.

Coloma, Rodrigo, Claudio Agüero y Renato Lira (2021). «Tecnología para decidir hechos en procesos judiciales». Revista Chilena de Derecho y Tecnología, 10 (1): 111-143. DOI: 10.5354/0719-2584.2021.56816.

De Verda y Beamonte, José (2014). «La incidencia del principio constitucional de libre desarrollo de la personalidad en la configuración del matrimonio». Revista Boliviana de Derecho, (17): 10-31. Disponible en https://bit.ly/3qQiJSM.

DíAz, Juliet, Adriana Pérez y René Florido (2011). «Impacto de las tecnologías de la información y las comunicaciones (TIC) para disminuir la brecha digital en la sociedad actual». Cultivos Tropicales, 32 (1): 81-9o. Disponible en https://bit. ly/3Fhtbab.

Donato, María, Sara Canepa, Laura Teffetani, Griselda Ezeiza, Fabriana Roglianno y Beatriz Pelitti (2020). «El derecho a la comunicación de las hijas y los hijos con sus progenitores en época de pandemia». El Derecho: Cuadernos Jurídicos de Derecho de Familia, 93: 1-5.

ETCHEBERRY, Leonor (2016). «La autorización de salida de los menores del país para radicarse en el extranjero de forma definitiva: Interés en conflicto. Alcances jurisprudenciales». En Manuel Barría Paredes (coordinador), Estudios de derecho Civil XI: Jornadas nacionales de Derecho Civil. Concepción, 2015 (pp. 129-139). Santiago de Chile: Thomson Reuters.

GonZÁLEZ, Noé (2009). «Revisión y renovación de la sociología de la familia». Espacio Abierto, 18 (3): 509-540. Disponible en https://bit.ly/3pcCFOi.

Gómez DE LA TORRE, Maricruz (2011). «La relación directa y regular como efecto de la ruptura». Revista del Magíster y Doctorado en Derecho, 4: 119-131. DOI: 10.5354/0718-5251.2012.18712.

Greeven, Nel (2016). «El cuidado personal de los niños en caso de muerte de ambos padres». Revista de Derecho de Familia, 2 (2): 65-89.

Hernández, María, Patricia López y Sheila Sánchez (2014). «La comunicación en la familia a través de las TIC. Percepción de los adolescentes». Revista de Educación Pulso, 37: 35-58.

Herrera, Paloma (2020). «El enfoque de género en la Política Nacional de Ciberseguridad de Chile». Revista de Derecho y Tecnología, 9 (1): 5-32. DOI: 10.5354/0719-2584.2020.51577.

IsLeR, Érika (2020). «La incidencia del covid-19 en el ejercicio de la garantía legal». Revista de Derecho (Universidad Católica del Norte), 27: 92-124. DOI: 10.22199/ issn.0718-9753-2020-0005. 
LATHROP, Fabiola (2010). «(In)constitucionalidad de la regla de atribución preferente materna del cuidado personal de los hijos del artículo 225 del Código Civil chileno». Ius et Praxis, 16 (2): 147-184. DOI: 10.4067/So718-00122010000200006.

LEDERMANN, Walter (2003). «El hombre y sus epidemias a través de la historia». Revista Chilena de Infectología, 20: 13-17. DOI: 10.4067/So716-10182003020200003.

Lennon, Viviane y Domingo Lovera (2011). « ¿Cuidado personal a partir del régimen de relación directa y regular? La importancia del Derecho internacional comparado». Revista Chilena de Derecho Privado, 17: 105-141. DOI: 10.4067/ So718-80722011000200004.

Lepin, Cristian (2013). "Reforma a las relaciones paternos-filiales: Análisis de la Ley N. ${ }^{\circ}$ 20.680». Revista de Derecho. Escuela de Postgrado, 3: 285-308. DOI: 10.5354/0719-5516.2014.31025.

Martínez, Leticia (2008). «La muerte negra». Disponible en https://bit.ly/3FuguvC. Mira, Andrea y Rodolfo Bastías (2021). «Maternidad, migración y prematuridad: Experiencias en una unidad de neonatología». Cuadernos Brasileiros de Terapia Ocupacional, (29): 1-19. DOI: 10.1590/2526-8910.ctoAO2232.

MondaCA, Alexis (2021). «De la particular necesidad de tutela de los niños, niñas $\mathrm{y}$ adolescentes que presentan algún trastorno del espectro autista en el contexto de la pandemia del covid-19: El difícil logro de estándares aceptables del manido "interés superior del niño"». En Cristian Lepín (coordinador), Covid-19. Santiago: Tirant lo Blanch.

Montecinos, Andrea (2018). «Interés superior del niño como fundamento de la autorización de su salida definitiva al extranjero». En Carmen Domínguez (coordinadora), Estudios de derecho de familia III: Terceras Jornadas Nacionales, Facultad de Derecho Pontificia Universidad Católica de Chile (pp. 569-589). Santiago: Thomson Reuters.

Oliva, Eduardo y Vera Villa (2014). «Hacia un concepto interdisciplinario de la familia en la globalización». Justicia Juris, 10 (1): 11-20. Disponible en https://bit. ly/3smRwrp.

ONU, Organización de Naciones Unidas, Cepal, Comisión Económica para América Latina y el Caribe, y Unicef, Fondo de las Naciones Unidas para la Infancia (2018). América Latina y el Caribe a 30 años de la aprobación de la Convención sobre los Derechos del Niño, 7. Disponible en https://bit.ly/3Dz416g.

OrTíz, Leonardo y Pablo Viollier (2021). «Repensando el derecho al olvido y la necesidad de su consagración legal en Chile». Revista Chilena de Derecho y Tecnología, 10 (1): 77-109. DOI: 10.5354/0719-2584.2021.56482.

Pfeffer, Emilio (2002). «Estados de excepción constitucional y reforma constitucional». Ius et Praxis, 8 (1): 223-250. DOI: 10.4067/So718-00122002000100013.

RavetLlat, Isaac y Ruperto Pinochet (2015). «El interés superior del niño en el marco de la Convención Internacional sobre los Derechos del Niño y su configuración 
en el Derecho civil». Revista Chilena de Derecho, 42 (3): 903-934. DOI: 10.4067/ So718-34372015000300007.

RICCI, Eduardo (2010). «Historia y análisis jurídico de los estados de excepción constitucional en Chile: El rol de las FF. AA.». Revista Marina, 127 (916): 219-231. Disponible en https://bit.ly/3Fvzd6T.

Ríos, Lautaro (2002). «Los estados de excepción constitucional en Chile». Ius et Praxis, 8 (1): 251-282. DOI: 10.4067/So718-00122002000100014.

RizıK, Lucía (2019). «La responsabilidad parental y las nuevas tecnologías de la información y la comunicación». En Alexis Mondaca y Cristián Aedo (editores), Estudios de derecho de familia IV: Cuartas Jornadas Nacionales, Facultad de Ciencias Jurídicas de la Universidad Católica del Norte (pp. 443-46o). Santiago de Chile: Thomson Reuters.

SÁncheZ-DAvis, Carlos (2008). "La muerte negra: el avance de la peste». Revista Med, 16 (1): 133-135. Disponible en https://bit.ly/3sgHSHo.

TAPIA, Mauricio (2020). Caso fortuito o fuerza mayor. Santiago: Thomson Reuters.

TAVARES, Regina (2016). «La guarda de niños no es posesión o propiedad». En Mario Delgado (coordinador), Guarda compartida (pp. 271-288). Sao Paulo: Método.

VARSI, Enrique, Nelson Rosenvald y Marco Torres (2020). «La pandemia del covid-19, la fuerza mayor y la alteración de las circunstancias en materia contractual». Acta Bioethica, 26 (1): 29-36. DOI: 10.4067/S1726-569X2020000100029.

\section{Sobre las autoras}

Constanza Astudillo Meza es abogada. Magíster en Derecho por la Universidad Católica de Chile y diplomada en Derecho de la Infancia y Adolescencia por la Universidad de Los Andes, Chile. Profesora de Derecho Civil de la Facultad de Derecho en la Universidad Santo Tomás, sede Antofagasta, Chile. Su correo electrónico es castudillom@santotomas.cl. (D) https://orcid.org/oooo-0o01-9796-3492.

Alexis Mondaca Miranda es abogado. Doctor en Derecho por la Pontificia Universidad Católica de Valparaíso, Chile y Diplomado en Bioética por la Pontificia Universidad Católica de Chile. Profesor de Derecho Civil de la Facultad de Ciencias Jurídicas y Sociales de la Universidad de Talca, Chile. Su correo electrónico es alexis. mondaca@utalca.cl. (D) https://orcid.org/oooo-0oo2-6559-4124. 


\title{
REVISTA CHILENA DE DERECHO Y TECNOLOGÍA
}

La Revista Chilena de Derecho y Tecnología es una publicación académica semestral del Centro de Estudios en Derecho Informático de la Facultad de Derecho de la Universidad de Chile, que tiene por objeto difundir en la comunidad jurídica los elementos necesarios para analizar y comprender los alcances y efectos que el desarrollo tecnológico y cultural han producido en la sociedad, especialmente su impacto en la ciencia jurídica.

\author{
EDITOR GENERAL \\ Daniel Álvarez Valenzuela \\ (dalvarez@derecho.uchile.cl) \\ SITIO WEB \\ rchdt.uchile.cl \\ CORREO ELECTRÓNICO \\ rchdt@derecho.uchile.cl \\ LICENCIA DE ESTE ARTÍ́CULO \\ Creative Commons Atribución Compartir Igual 4.o Internacional
}

\begin{abstract}
s
La edición de textos, el diseño editorial

y la conversión a formatos electrónicos de este artículo

estuvieron a cargo de Tipográfica

(www.tipografica.io).
\end{abstract}

